\title{
Evaluation of the Retina, Choroid and Optic Disc Vascular Structures In Individuals With a History of Covid-19
}

\section{Birumut Gedik ( $\nabla$ www.birumutgedik@hotmail.com )}

Antalya Serik State Hospital: Antalya Serik Devlet Hastanesi https://orcid.org/0000-0002-9163-1187

\section{Ozdemır Yuksel}

Antalya Training and Research Hospital: Antalya Egitim ve Arastirma Hastanesi

\section{Muhammet Kazim Erol}

Antalya Training and Research Hospital: Antalya Egitim ve Arastirma Hastanesi

Fulya Duman

Antalya Training and Research Hospital: Antalya Egitim ve Arastirma Hastanesi

\section{Berna Dogan}

Antalya Training and Research Hospital: Antalya Egitim ve Arastirma Hastanesi

\section{Elcin Suren}

Antalya Training and Research Hospital: Antalya Egitim ve Arastirma Hastanesi

\section{Sibel Yavuz}

Antalya Training and Research Hospital: Antalya Egitim ve Arastirma Hastanesi

\section{Research Article}

Keywords: Choriocapillaris blood flow, choroid thickness, coronavirus, COVID-19, optic coherence tomography angiography

Posted Date: March 3rd, 2022

DOI: https://doi.org/10.21203/rs.3.rs-1300394/v1

License: (1) (i) This work is licensed under a Creative Commons Attribution 4.0 International License. Read Full License 


\section{Abstract}

\section{Introduction}

In this study, we aimed to detect changes in posterior segment structures and posterior segment vascular density caused by COVID-19 using the optical coherence tomography angiography (OCTA) device.

\section{Material and Method}

The study included 20 eyes of 20 patients without any systemic or eye disease, who were followed up at the Ophthalmology Clinic of Health Sciences University Antalya Training and Research Hospital. The OCTA images of these individuals taken before COVID-19 and at six months after recovery were examined.

\section{Results}

The mean choriocapillaris blood flow value of the patients was $2.00 \pm 0.13 \mathrm{~mm}^{2}$ before COVID-19 and $2.08 \pm 0.23 \mathrm{~mm}^{2}$ after the disease, the mean subfoveal choroidal thickness value was $247.33 \pm 7.65 \mu \mathrm{m}$ before the disease and $273.08 \pm 4.92 \mu \mathrm{m}$ after the disease, indicating a statistically significant difference $(p=0.003, p=0.001$, respectively). The mean retinal nerve fiber layer values before and after COVID-19 were $119.33 \pm 3.88$ and $117.50 \pm 3.92 \mu \mathrm{m}$, respectively, and there was a statistically significant decrease $(p<0.001)$.

\section{Conclusion}

This is the first study in the literature to evaluate the post-COVID-19 changes in the eye vascular structures compared to the pre-disease values. We consider that inflammation and increased vascular permeability are effective in changes.

\section{Introduction}

Coronaviruses, belonging to the RNA virus family, can cause infections in both humans and animals. Coronavirus disease is an infectious disease caused by severe acute respiratory syndrome coronavirus 2 (SARS-CoV-2). The disease caused by this virus was named COVID-19, where "CO" stands for corona, "VI" for virus, " $D$ " for disease, and " 19 " indicates the year in which it occurred. COVID-19 is a systemic disease affecting the whole body and manifesting with the general findings of fever, cough, fatigue, headache, sore throat, loss of taste, loss of smell, and low back pain [1, 2]. In this disease, ocular findings can also be seen and sometimes even present as initial findings. Ocular findings associated with COVID-19 include eye watering, itching, foreign body sensation, double vision, blurred vision, limitation of eye movements, conjunctivitis, Guillain-Barré syndrome, chemosis, lagophthalmia and ischemic optic neuropathy [3, 4].

Optical coherence tomography angiography (OCTA) is a non-invasive imaging modality that has recently been used to visualize retinal vascular blood flow. OCTA can measure both the superficial and deep 
vessel densities in the macular capillary plexus by detecting motion contrast in blood flow [5]. In previous studies, retinal and choroidal vascular density values in patients with COVID-19 were compared with control groups using OCTA, and statistically significant results were obtained [6, 7]. The current study aimed to compare the retinal, choroidal and optic disc vascular density values, choroidal thickness, and retinal nerve fiber layer (RNFL) of the same individuals before and after COVID-19 using the OCTA device. We conducted this study with the hypothesis that changes in the posterior segment structures and posterior segment vascular density caused by COVID-19 can be detected using the OCTA device.

\section{Material And Method Patient Selection}

The study included 20 eyes of 20 individuals without any systemic or eye disease, who were followed up at the Ophthalmology Clinic of Health Sciences University Antalya Training and Research Hospital. These individuals consisted of healthcare workers who had been selected as a control group for another academic study before the COVID-19 pandemic and later contracted the virus but recovered without the need for intensive care. The complete ophthalmologic examinations and OCTA findings of these patients before COVID-19 and at six-month after recovery from the disease were recorded from their files. This study was carried out between 01.01.20 - 01.01.21. None of the patients in this study received a coronavirus related vaccine.

The exclusion criteria were determined as follows: any eye pathology (e.g., glaucoma, uveitis, diabetic retinopathy, amblyopia, and epiretinal membrane), myopia greater than -6 diopters, axial length greater than $26 \mathrm{~mm}$, history of eye surgery other than uncomplicated cataract surgery, and any systemic disease.

The demographic characteristics of the patients (age, gender, medications, systemic disease, etc.) and examination findings were available in patient files. A full ophthalmological examination and OCTA were performed before COVID-19 and during follow-up at six months after the disease. The findings of the fundus examinations of the patients were evaluated by biomicroscopy. The OCTA images of the patients were examined. A spectral-domain OCTA device (AngioVue; Optovue, Inc, Fremont, CA) was used to obtain OCTA images.

\section{Octa Evaluation}

The OCTA measurements of the patients were performed on the $6 \times 6 \mathrm{~mm} \mathrm{HD}$ angio retina and $4.5 \times 4.5$ $\mathrm{mm}$ AngioDisc scales. Images with poor shooting quality due to motion and other artifacts were not included in the study. Only images with a signal quality higher than $8 / 10$ were evaluated. The foveal vascular density was measured from a 1-mm circular region, parafoveal vascular density from a $1 \mathrm{~mm} x$ $3 \mathrm{~mm}$ circular region, perifoveal vascular density from a $1 \mathrm{~mm} \times 3 \mathrm{~mm}$ circular region, and total vascular density from a $6 \mathrm{~mm}$ circular region in the center of the fovea, and all the values were recorded as percentages. These areas provided the density measurement of the superficial capillary area in automatic 
mode in cross-section. The ratio of the vascular image (white areas) in these regions to the whole area was used as percentage density.

The foveal avascular zone (FAZ) was automatically calculated by the device from as a measurement in $\mathrm{mm}^{2}$. Choriocapillaris blood flow (CBF) was automatically calculated as the amount of area with blood flow in the choriocapillaris layer with a central radius of $1 \mathrm{~mm}$ and an area of $3.142 \mathrm{~mm}^{2}$ and was recorded in $\mathrm{mm}^{2}$ [Figure 1, 2]. Optic disc vascular density was obtained as vascular density measured from a $4.5 \mathrm{~mm}$ circular region centered on the optic disc and recorded as a percentage. RNFL was automatically measured and recorded by the device from a $3.4 \mathrm{~mm}$ scanning circle centered on the optic disc [Figure 3, 4]. Retinal thicknesses were automatically measured between internal limiting membrane and retinal pigment epithelium in the foveal, parafoveal and perifoveal regions and recorded by the device.

Choroidal thickness measurements were performed from the subfoveal area by two different observers using the "Enhanced HD line" image. The average of the measurements of the two observers was calculated. The RPE-sclerachoroidal junction was taken as the boundary of the subfoveal choroidal thickness (SCT).

\section{Statistical Analysis}

The analysis of the data was performed using SPSS v. 24.0 software package. Descriptive statistics were given as percentages for categorical variables, and mean, standard deviation and median, minimum and maximum values for numerical variables. The conformity of the numerical variables to the normal distribution was evaluated with the Shapiro-Wilk test. Values were presented using mean and standard deviation. Pre- and post-disease measurements were compared using the Wilcoxon test. The results were evaluated at the $95 \%$ confidence interval, and $p<0.05$ was considered statistically significant.

\section{Results}

The mean age of the 20 participants, twelve female and eight male, was calculated as $36.70 \pm 1.81$ years. None of the patients had pneumonia, and their bleeding profile values (active partial thromboplastin time, prothrombin time, INR, D-dimer, and fibrinogen) were normal. The oxygen saturation of all the patients varied between 94 and 100\%, and none required oxygen therapy. All the patients received favipiravir and anticoagulant therapy. None of the patients required hospitalization or received steroid therapy. The demographic characteristics of the patients are given in Table 1. 
Table 1

Demographic characteristics of the patients participating in the study

\begin{tabular}{|ll|}
\hline Variable & Value \\
\hline Age & $36.70 \pm 1.81$ \\
\hline Female/Male & $12 / 8$ \\
\hline Number of doctors & 4 \\
\hline Number of nurses & 4 \\
\hline Number of medical secretaries & 10 \\
\hline Number of other healthcare personnel & 2 \\
\hline Total number of patients & 20 \\
\hline
\end{tabular}

Burning and stinging were present in six of the 20 patients (30\%), redness in four (20\%), itching in ten (50\%), eye pain in twelve (60\%), and visual impairment in four (20\%) patients, while four patients did not have any ocular symptoms. Epiphora, conjunctivitis and neuroophthalmologic symptoms were not detected in any of the patients.

Table 2 presents the comparison of the superficial capillary plexus (SCP) and deep capillary plexus (DCP) vascular density values measured by OCTA before and after COVID-19. No statistically significant difference was found in the comparison of the pre- and post-disease vascular density values of SCP and DCP. 
Table 2

Comparison of the superficial and deep capillary plexus vascular densities before and after COVID-19

\begin{tabular}{|c|c|c|c|c|c|c|c|}
\hline & Group & $\mathbf{N}$ & Mean & SD & Min & Max & $\mathbf{P}$ \\
\hline SCP total vascular & Pre-disease & 20 & 52.78 & 1.04 & 48.40 & 57.50 & 0.47 \\
\hline density (\%) & Post-disease & 20 & 52.63 & 0.99 & 47.60 & 56.90 & \\
\hline SCP foveal vascular & Pre-disease & 20 & 17.80 & 1.08 & 13.10 & 23.20 & 0.65 \\
\hline Density (\%) & Post-disease & 20 & 17.04 & 1.43 & 11.10 & 24.80 & \\
\hline \multirow{2}{*}{$\begin{array}{l}\text { SCP parafoveal vascular } \\
\text { density (\%) }\end{array}$} & \multirow{2}{*}{$\begin{array}{l}\text { Pre-disease Post- } \\
\text { disease }\end{array}$} & 20 & 54.93 & 1.24 & 48.10 & 60.10 & 0.44 \\
\hline & & 20 & 54.21 & 1.39 & 46.10 & 59.40 & \\
\hline \multirow{2}{*}{$\begin{array}{l}\text { SCP perifoveal vascular } \\
\text { density (\%) }\end{array}$} & \multirow{2}{*}{$\begin{array}{l}\text { Pre-disease Post- } \\
\text { disease }\end{array}$} & 20 & 53.43 & 1.10 & 48.60 & 58.40 & 0.74 \\
\hline & & 20 & 53.48 & 1.04 & 48.50 & 58 & \\
\hline \multirow{2}{*}{$\begin{array}{l}\text { DCP total vascular } \\
\text { density (\%) }\end{array}$} & \multirow{2}{*}{$\begin{array}{l}\text { Pre-disease Post- } \\
\text { disease }\end{array}$} & 20 & 55.20 & 0.73 & 48 & 58.50 & 0.36 \\
\hline & & 20 & 55.80 & 1.09 & 49.50 & 61.70 & \\
\hline \multirow{2}{*}{$\begin{array}{l}\text { DCP foveal vascular } \\
\text { density (\%) }\end{array}$} & \multirow{2}{*}{$\begin{array}{l}\text { Pre-disease Post- } \\
\text { disease }\end{array}$} & 20 & 35.45 & 1.89 & 27.40 & 46.40 & 0.89 \\
\hline & & 20 & 34.68 & 2.27 & 25.10 & 45.70 & \\
\hline \multirow{2}{*}{$\begin{array}{l}\text { DCP parafoveal vascular } \\
\text { density (\%) }\end{array}$} & \multirow{2}{*}{$\begin{array}{l}\text { Pre-disease Post- } \\
\text { disease }\end{array}$} & 20 & 58.41 & 0.64 & 52.20 & 60.10 & 0.35 \\
\hline & & 20 & 58.87 & 1.04 & 53 & 63.20 & \\
\hline \multirow{2}{*}{$\begin{array}{l}\text { DCP perifoveal vascular } \\
\text { density (\%) }\end{array}$} & \multirow{2}{*}{$\begin{array}{l}\text { Pre-disease Post- } \\
\text { disease }\end{array}$} & 20 & 57.07 & 0.74 & 50 & 60 & 0.34 \\
\hline & & 20 & 57.71 & 1.11 & 51 & 63 & \\
\hline
\end{tabular}

Table 3 shows the comparison of the FAZ, CBF, SCT and retinal thickness values measured using OCTA before and after COVID-19. No statistically significant difference was found in the comparison of the preand post-disease FAZ and retinal thickness values. The mean CBF value of the patients was $2.00 \pm 0.13$ $\mathrm{mm}^{2}$ before COVID-19 and $2.08 \pm 0.23 \mathrm{~mm}^{2}$ after the disease. When the pre- and post-disease CBF values were compared, there was a statistically significant increase $(p=0.003)$. The mean SCT value was $247.33 \pm 7.65 \mu \mathrm{m}$ before COVID-19 and $273 \pm 4.92 \mu \mathrm{m}$ after the disease, indicating a statistically significant increase $(p=0.001)$. 
Table 3

Comparison of foveal avascular zone, choriocapillaris blood flow, subfoveal choroidal thickness and total retinal thickness before and after COVID-19

\begin{tabular}{|c|c|c|c|c|c|c|c|}
\hline & Group & $\mathbf{N}$ & Mean & SD & Min & Max & $\mathbf{P}$ \\
\hline \multirow[t]{2}{*}{ Foveal avascular zone $\left(\mathrm{mm}^{2}\right)$} & Pre-disease & 20 & 0.32 & 0.36 & 0.16 & 0.49 & 0.16 \\
\hline & $\begin{array}{l}\text { Post- } \\
\text { disease }\end{array}$ & 20 & 0.32 & 0.38 & 0.16 & 0.50 & \\
\hline \multirow[t]{2}{*}{ Choriocapillaris blood flow $\left(\mathrm{mm}^{2}\right)$} & Pre-disease & 20 & 2 & 0.13 & 1.90 & 2.04 & 0.003 \\
\hline & $\begin{array}{l}\text { Post- } \\
\text { disease }\end{array}$ & 20 & 2.08 & 0.23 & 1.94 & 2.18 & \\
\hline \multirow[t]{2}{*}{ Subfoveal choroidal thickness $(\mu \mathrm{m})$} & Pre-disease & 20 & 247.33 & 7.65 & 205 & 286 & 0.001 \\
\hline & $\begin{array}{l}\text { Post- } \\
\text { disease }\end{array}$ & 20 & 273.08 & 4.92 & 249 & 296 & \\
\hline \multirow{2}{*}{$\begin{array}{l}\text { Total retina parafoveal thickness } \\
(\mu \mathrm{m})\end{array}$} & Pre-disease & 20 & 239.75 & 2.48 & 226 & 252 & 0.92 \\
\hline & $\begin{array}{l}\text { Post- } \\
\text { disease }\end{array}$ & 20 & 239.67 & 2.94 & 221 & 253 & \\
\hline \multirow[t]{2}{*}{ Total retina foveal thickness $(\mu \mathrm{m})$} & Pre-disease & 20 & 314.50 & 3.40 & 303 & 332 & 0.79 \\
\hline & $\begin{array}{l}\text { Post- } \\
\text { disease }\end{array}$ & 20 & 313.67 & 3.74 & 301 & 337 & \\
\hline \multirow{2}{*}{$\begin{array}{l}\text { Total retina perifoveal thickness } \\
(\mu \mathrm{m})\end{array}$} & Pre-disease & 20 & 293.50 & 1.71 & 286 & 301 & 0.91 \\
\hline & $\begin{array}{l}\text { Post- } \\
\text { disease }\end{array}$ & 20 & 293.17 & 2.28 & 284 & 306 & \\
\hline
\end{tabular}

Table 4 presents the comparison of the optic disc vascular density and RNFL values measured before and after COVID-19. No statistically significant difference was found in the comparison of the optic disc vascular density values before and after COVID-19. While the mean RNFL value was $119.33 \pm 3.88 \mu \mathrm{m}$ before COVID-19, it was measured as $117.50 \pm 3.92 \mu \mathrm{m}$ after the disease, indicating a statistically significant decrease $(p<0.001)$. 
Table 4

Comparison of the optic disc total vessel vascular density and retinal nerve fiber layer thickness values before and after COVID-19

\begin{tabular}{|c|c|c|c|c|c|c|c|}
\hline & Group & $\mathbf{N}$ & Mean & SD & Min & Max & $\mathbf{P}$ \\
\hline Optic disc total & Pre-disease & 20 & 57.87 & 0.39 & 56 & 59.60 & \\
\hline vascular density (\%) & $\begin{array}{l}\text { Post- } \\
\text { disease }\end{array}$ & 20 & 57.52 & 0.34 & 54.80 & 59.20 & 0.44 \\
\hline \multirow[t]{2}{*}{ Inside-disc vascular density (\%) } & Pre-disease & 20 & 61.83 & 0.56 & 59.60 & 64.80 & 0.50 \\
\hline & $\begin{array}{l}\text { Post- } \\
\text { disease }\end{array}$ & 20 & 60.40 & 0.67 & 57.10 & 63.70 & \\
\hline \multirow{2}{*}{$\begin{array}{l}\text { Peripapillary vascular density } \\
\text { (\%) }\end{array}$} & Pre-disease & 20 & 59.45 & 0.42 & 57.30 & 61.40 & 0.30 \\
\hline & $\begin{array}{l}\text { Post- } \\
\text { disease }\end{array}$ & 20 & 59.57 & 0.54 & 55.70 & 61.20 & \\
\hline \multirow[t]{2}{*}{ Retinal nerve fiber layer $(\mu \mathrm{m})$} & Pre-disease & 20 & 119.33 & 3.88 & 101 & 127 & $<0.001$ \\
\hline & $\begin{array}{l}\text { Post- } \\
\text { disease }\end{array}$ & 20 & 117.50 & 3.92 & 98 & 124 & \\
\hline
\end{tabular}

\section{Discussion}

COVID-19 is a systemic disease that affects the whole body, especially the respiratory tract. The main symptoms of COVID-19 are fever, cough, sore throat, and loss of smell and taste. Ocular symptoms can also be seen and sometimes even present as initial findings [8]. Bertoli et al. reported conjunctivitis, Kawasaki disease, Guillain-Barré syndrome, polyneuritis, encephalopathy, dry eye, exposure keratopathy, chemosis, infectious keratitis, ischemic optic neuropathy, and Horner syndrome in patients with COVID-19 [4]. Wu et al. found ocular symptoms, including conjunctivitis, conjunctival hyperemia, epiphora, chemosis and increased secretion in 12 (31.6\%) of 38 patients with COVID-19 [9]. In another study, Zhou et al. noted the presence of conjunctival symptoms, such as chemosis, conjunctival hyperemia, itching, foreign body sensation, and watering in eight (6.6\%) of 121 COVID-19 cases [10]. Hon et al., evaluating 56 patients with COVID-19, observed ocular symptoms in $15(27 \%)$ patients and summarized these symptoms as itching, redness, foreign body sensation, dry eyes, watering and floating objects. The authors also noted that six $(11 \%)$ patients had developed ocular symptoms prior to respiratory system symptoms [11].

Marinho et al. examined 12 patients with COVID-19 and found soft exudate in the retina, retinal hemorrhage, and hyperreflectivity in ganglion cells and inner plexiform on optical coherence tomography [12]. In another study, Virgo et al. observed acute macular neuroretinopathy in a patient with COVID-19 and paracentral moderate acute retinopathy in another case [13]. Tostmann et al. described eye pain in 
31 (34.4\%) of 90 patients with COVID-19 [14] while Mao et al. reported visual loss in three $(1.4 \%)$ of 214 patients [15]. In COVID-19 cases, Guillain-Barré syndrome manifesting with diplopia, third or sixth nerve involvement, and nystagmus, as well as its eye component, Miller Fisher syndrome, have also been described $[16,17]$. However, although literature studies have shown that coronaviruses cause anterior uveitis, retinitis, vasculitis and choroiditis in animals, these findings have not been found in humans [18].

The etiopathogenesis of ocular findings seen in COVID-19 has been investigated in various studies but has not yet been fully elucidated. Considering the pathogenesis of conjunctivitis symptoms, it is thought that the virus uses the ocular surface as an entry point through the mediation of angiotensin-converting enzyme 2 receptors [19]. Peripheral nerve damage, demyelination and inflammation in diplopia are held responsible for visual impairment [20]. In Guillain-Barré and Miller Fisher syndromes, the autoimmune mechanism has been suggested to be effective against Schwann cells and myelin antigens $[16,17,20]$.

Savastano et al. compared the OCTA findings of 80 patients with COVID-19 to 30 healthy controls. The authors reported the mean RNFL value as $94.09 \pm 10.77 \mu \mathrm{m}$ for the COVID-19 group and $96.50 \pm 7.78 \mu \mathrm{m}$ for the control group. Although this difference was not statistically significant, the RNFL value of the COVID-19 control was found to be lower than the control group $(p=0.26)$ [21]. In the current study, the mean RNFL was $119.33 \pm 3.88 \mu \mathrm{m}$ before COVID-19 and $117.50 \pm 3.92 \mu \mathrm{m}$ after the disease. The decrease in the RNFL value after the disease was statistically significant $(p<0.001)$. We consider that the reason for this is inflammation and retinal nerve fiber damage, as also described in previous studies [20].

Various OCTA studies have been conducted in relation to COVID-19 and its vascular etiopathogenesis. Abrishami et al. compared the OCTA findings of 30 patients with COVID-19 (nine requiring hospitalized treatment) obtained at two weeks after recovery to 23 healthy individuals. The total, parafoveal and foveal vascular density values of SCP and DCP were found to be statistically significantly lower in the COVID-19 group $(p=0.001, p=0.002, p=0.004, p=0.001, p=0.011$, and $p=0.003$, respectively [6]. Similarly, Cennoma et al. evaluated the OCTA values at six months after recovery in 40 patients who had developed pneumonia due to COVID-19 and compared them to 40 healthy individuals. The authors reported that the total vascular densities of the optic disc and SCP and the total, parafoveal and foveal vascular densities of DCP were statistically significantly lower in the COVID-19 group compared to the control group $\left(p<0.001, p=0.038, p=0.029, p=0.016\right.$, and $p=0.027$, respectively). ${ }^{7}$ In another study, Savastano et al. found the radial peripapillary plexus perfusion density to be statistically significantly lower in individuals with COVID-19 compared to the control group, and this difference statistically significant $(p=0.041)$ [21].

In a study evaluating OCTA findings in 27 patients with a history of COVID-19 at one week after recovery from the disease compared to a healthy control group, Turker et al. observed a statistically significant decrease in the parafoveal vascular density values of SCP and DCP in the COVID-19 group $(p<0.05)$. However, the foveal vascular density did not statistically significant differ between the two groups. In the same study, the CBF value was reported to be $2.15 \pm 0.23 \mathrm{~mm}^{2}$ for the COVID-19 group and $2.08 \pm 0.11$ $\mathrm{mm}^{2}$ for the control group, indicating a statistically significant difference $(p=0.042)$ [22]. In our study, 
when we compared the retinal and optic disc vascular density values of the same patients before and after COVID-19, we found no statistically significant results. While the mean CBF value of the patients was $2.00 \pm 0.13 \mathrm{~mm}^{2}$ before COVID-19, it was $2.08 \pm 0.23 \mathrm{~mm}^{2}$ after the disease. When the pre-and postdisease CBF values, there was a statistically significant increase in the post-disease CBF value $(p=$ 0.003).

In an autopsy performed on a person who died due to COVID-19, SARS-CoV-2 ribonucleic acid was detected in the retina [23]. Since there are ACE2 receptors in the retina and choroid, these tissues also have binding sites for the SARS-CoV-2 virus [6]. Studies have shown that COVID-19 causes vascular endothelial damage and vascular complications. Although endothelial damage, tissue edema, inflammatory cell migration, intravascular coagulation cascade, and endotheliitis are considered to be involved in vascular pathogenesis, the exact mechanism of this cascade remains unknown [24-26]. Inflammation and increased vascular permeability caused by COVID-19 are held responsible for the increase in CBF $[22,27]$. We consider that despite the increase in the CBF value, the vascular density values of the retina and optic disc were not altered by the disease due to the autoregulation mechanism in the retina [6]. In addition, the retina contains a blood retinal barrier, but there is no such barrier in the choroid. Therefore, while inflammation and increased vascular permeability cause an increase in CBF, no change is observed in retinal vascular density values. It has been suggested that individuals that have had severe COVID-19 can develop hypoxia, ischemia, and microvascular damage in the retina $[6,22,28]$. The absence of significant changes before and after COVID-19 in our study despite the decrease in retinal vascular density values in the literature may be related to the patients in previous studies suffering from a more severe form the disease requiring hospitalization.

Savastano et al. found the mean SCT value as $310.463 \pm 81.60 \mu \mathrm{m}$ in the patients with COVID-19 and $293.5 \pm 86.56 \mu \mathrm{m}$ in the control group. Although not statistically significant, the mean SCT value was higher in individuals who had a history of COVID-19 $(p=0.34)$ [21]. In our study, the mean SCT value was measured as $247.33 \pm 7.65 \mu \mathrm{m}$ before the disease and $273.08 \pm 4.92 \mu \mathrm{m}$ after the disease, and this increase was found to be statistically significant $(p=0.001)$.

Tan et al. listed the causes of an altered choroidal thickness as age-related changes, gender differences, sympathetic system activity, metabolic diseases (diabetes mellitus, hypercholesterolemia, etc.), changes due to choroidal hyperperfusion (hypertension), systemic inflammatory conditions (ankylosing spondylitis, Raynaud's phenomenon, Vogt-Koyanagi-Harada disease, Behçet's disease, and sarcoidosis), cerebral vasculature changes (Alzheimer's disease), microarteriolar occlusions (sickle cell disease), choroidal tumors and choroidal metastases [29]. We also consider that the increase in the choroidal thickness of our patients was caused by inflammation, increased vascular permeability, and increased CBF.

Considering the limitations of this study, it can be stated that the major limitation was the small number of patients. Another limitation is that none of the patients in this study required intensive care during active infection, and none had a severe form of the disease. Although the patients in our study did not 
experience severe COVID-19, we found changes in their CBF, SCT and RNFL values compared to the predisease period. The retina, choroid and optic disc may be affected more in severe COVID-19, and this may be reflected in results in the presence of larger data. We consider that our study will contribute to the literature by guiding further research to be conducted with larger samples.

\section{Conclusion}

This is the first study in the literature to evaluate the pre- and post-disease changes in the vascular values of the retina, choroid and optic disc in people that recovered from COVID-19. We consider that in individuals with a history of COVID-19, inflammation and increased vascular permeability are effective in increased CBF and SCT values compared to the pre-disease period. In addition, inflammation and destruction of the retinal nerve fiber may be responsible for the decrease in RNFL in these patients.

\section{Declarations}

Funding No funding was received for conducting this study.

Conflict of interest All authors declare no funding was received and no conflict of interest/competing interests.

Data availability The data supporting the findings of the study are available from the corresponding author upon request.

Code availability Not applicable.

Authors' contributions All authors contributed to the study conception and design. Material preparation, data collection, and analysis were performed by MKE, BG and OY. The first draft of the manuscript was written by BG and OY. MKE, BD, FD and ES read, revised, and approved the final manuscript.

Ethical approval The study protocol was approved by the Health Sciences University Antalya Training And Research Hospital (Date: 18.03.21 No:3/17). This article does not contain any studies with human participants or animals performed by any of the authors.

Consent to participate Written consent was acquired by all participants.

Consent for publication Written consent was acquired by all participants.

\section{References}

1. Abayomi A, Odukoya O, Osibogun A, et al (2021) Presenting Symptoms and Predictors of Poor Outcomes Among 2,184 Patients with COVID-19 in Lagos State, Nigeria. International Journal of Infectious Diseases. 102: 226-232. https://doi.org/10.1016/j.ijid.2020.10.024. 
2. Guan WJ, Ni ZY, Hu Y, et al (2020) Clinical characteristics of coronavirus disease 2019 in China. New England Journal of Medicine. 382(18): 1708-1720. https://doi.org/ 10.1056/NEJMoa2002032.

3. Xia J, Tong J, Liu M, et al (2020) Evaluation of coronavirus in tears and conjunctival secretions of patients with SARS-CoV-2 infection. J Med Virol.92(6):589-594. https://doi.org/10.1002/jmv.25725

4. Bertoli F, Veritti D, Danese C, et al (2020) Ocular Findings in COVID-19 Patients: A review of Direct Manifestations and Indirect Effects on the Eye. Journal of Ophthalmology. Vol 2020, Article ID 4827304, 9 pages. https://doi.org/10.1155/2020/4827304.

5. Gedik B, Suren S, Bulut M, et al (2021) Changes in choroidal blood flow in patients with macular hole after surgery. Photodiagnosis and Photodynamic Therapy. 35: 102428. https://doi.org/10.1016/j.pdpdt.2021.102428

6. Abrishami M, Emamverdian Z, Shoeibi N, et al (2021) Optical coherence tomography angiography analysis of the retina in patients recovered from COVID-19: a case-control study. Canadian Journal of Ophthalmology. 56(1): 24-30. https://doi.org/10.1016/j.jcjo.2020.11.006.

7. Cennamo G, Reibaldi M, Montorio D, et al (2021) Optical Coherence Tomography Angiography Features in Post-COVID-19 Pneumonia Patients: A Pilot Study. American Journal of Ophthalmology. 227: 182-190. https://doi.org/10.1016/j.ajo.2021.03.015.

8. La Torre G, Massetti AP, Antonelli G, et al (2020) Anosmia and Ageusia as Predictive Signs of COVID19 in Healthcare Workers in Italy: A Prospective Case-Control Study.Journal of Clinical Medicine. 9(9):2870. https://doi.org/10.3390/jcm9092870.

9. Wu P, Duan F, Luo C, et al (2020) Characteristics of Ocular Findings of Patients With Coronavirus Disease 2019 (COVID-19) in Hubei Province, China. JAMA Ophthalmol. 138(5): 575-578. https://doi:10.1001/jamaophthalmol.2020.1291

10. Zhou Y, Duan C, Zeng Y, et al (2020) Ocular findings and proportion with conjunctival SARS-COV-2 in COVID-19 patients. Ophthalmology. 127: 981-982. https://doi.org/10.1016/j.ophtha.2020.04.028.

11. Hong N, Yu W, Xia J, et al (2020) Evaluation of ocular symptoms and tropism of SARS-CoV-2 in patients confirmed with COVID-19. Acta Ophthalmol. 2020;1-7. https://doi.org/1111/aos.14445.

12. Marinho PM, Marcos AAA, Romano AC, et al (2020) Retinal findings in patients with COVID-19. Lancet. 395: 1610. https://doi.org/10.1016/S0140-6736(20)31014-X.

13. Virgo J, Mohamed M (2020) Paracentral acute middle maculopathy and acute macular neuroretinopathy following SARS-CoV-2 infection. Eye. 34: 2352-3. https://doi.org/10.1038/s41433020-1069-8.

14. Tostmann A, Bradley J, Bousema T, et al (2020) Strong associations and moderate predictive value of early symptoms for SARS-CoV-2 test positivity among healthcare workers, the Netherlands, March 2020. Eurosurveillance. 25: 16. https://doi.org/10.2807/1560-7917. es.2020.25.16.200050856.

15. Mao L, Jin H, Wang M, et al (2020) Neurologic manifestations of hospitalized patients with coronavirus disease 2019 in Wuhan, China. JAMA Neurol. 77(6): 683-690. https://doi.org/10.1001/jamaneurol.2020.1127 
16. Dinkin M, Gao V, Kahan J, et al (2020) COVID-19 presenting with ophthalmoparesis from cranial nerve palsy. Neurology. 95 (5): 221-223 https://doi.org/10.1212/WNL.0000000000009700

17. Gutiérrez-Ortiz C, Méndez A, Rodrigo-Rey S, et al (2020) Miller Fisher Syndrome and polyneuritis cranialis in COVID-19. Neurology. 2020, 95 (5): 601-605. https://doi.org/10.1212/wnl.0000000000009619.

18. Seah I, Agrawal R (2020) Can the coronavirus disease 2019 (COVID-19) affect the eyes? a review of coronaviruses and ocular implications in humans and animals. Ocul Immunol Inflamm. 28(3): 391395. https://doi.org/:10.1080/09273948.2020.173850128.

19. Zhou L, Xu Z, Castiglione GM, et al (2020) ACE2 and TMPRSS2 are expressed on the human ocular surface, suggesting susceptibility to SARS-CoV-2 infection. Ocular Surface. 18(4): 537-544. https://doi.org/10.1016/j.jtos.2020.06.007.

20. Lusi ME, Mota C, Maleita D, et al (2020) A Review of Neuro-Ophthalmological Manifestations of Human Coronavirus Infection. Eye and Brain. 12: 129-137. https://doi.org/2147/EB.S268828.

21. Savastano A, Crincoli E, Savastano MC, et al (2020) Peripapillary retinal vascular involvement in early post-COVID-19 patients. J Clin Med. 9: 2895. https://doi.org/10.3390/jcm9092895.

22. Turker IC, Dogan CU, Guven D, et al (2021) Optical coherence tomography angiography findings in patients with COVID-19. Can J Ophthalmol. 56(2): 83-87. https://doi.org/1016/j.jcjo.2020.12.021.

23. Casagrande M, Fitzek A, Puschel K, et al (2020) Detection of SARSCoV-2 in human retinal biopsies of deceased COVID-19 patients. Ocul Immunol Inflamm. 28(5): 721-725.

https://doi.org/10.1080/09273948.2020.1770301

24. McCarthy CG, Wilczynski S, Wenceslau CF, Webb RC (2021) A new storm on the horizon in COVID-19: Bradykinin-induced vascular complications. Vascul Pharmacol.137: 106826. https://doi.org/1016/j.vph.2020.106826.

25. Griffin DO, Jensen A, Khan M, et al (2020) Arterial thromboembolic complications in COVID-19 in lowrisk patients despite prophylaxis. Br J Haematol. https://doi.org/10.1111/bjh.16792.

26. Varga Z, Flammer AJ, Steiger P, et al (2020) Endothelial cell infection and endothelitis in COVID19. 395: 1417-1418. https://doi.org/10.1016/S0140-6736(20)30937-5.

27. Hirooka K, Saito W, Namba K, et al (2015) Graefe's Archive for Clinical and Experimental Ophthalmology. 253: 609-617. https://doi.org /10.1007/s00417-014-2927-5.

28. Magro C, Mulvey JJ, Berlin D, et al. (2020) Complement associated microvascular injury and thrombosis in the pathogenesis of severe COVID-19 infection: a report of five cases. Transl Res. 220: 1-13. https://doi.org/10.1016/j.trsl.2020.04.007.

29. Tan KA, Gupta P, Agarwal A, et al (2016) State of science: Choroidal thickness and systemic health. Survey of Ophthalmology. 61(5): 566-581. https://doi.org/10.1016/j.survophthal.2016.02.007.

\section{Figures}




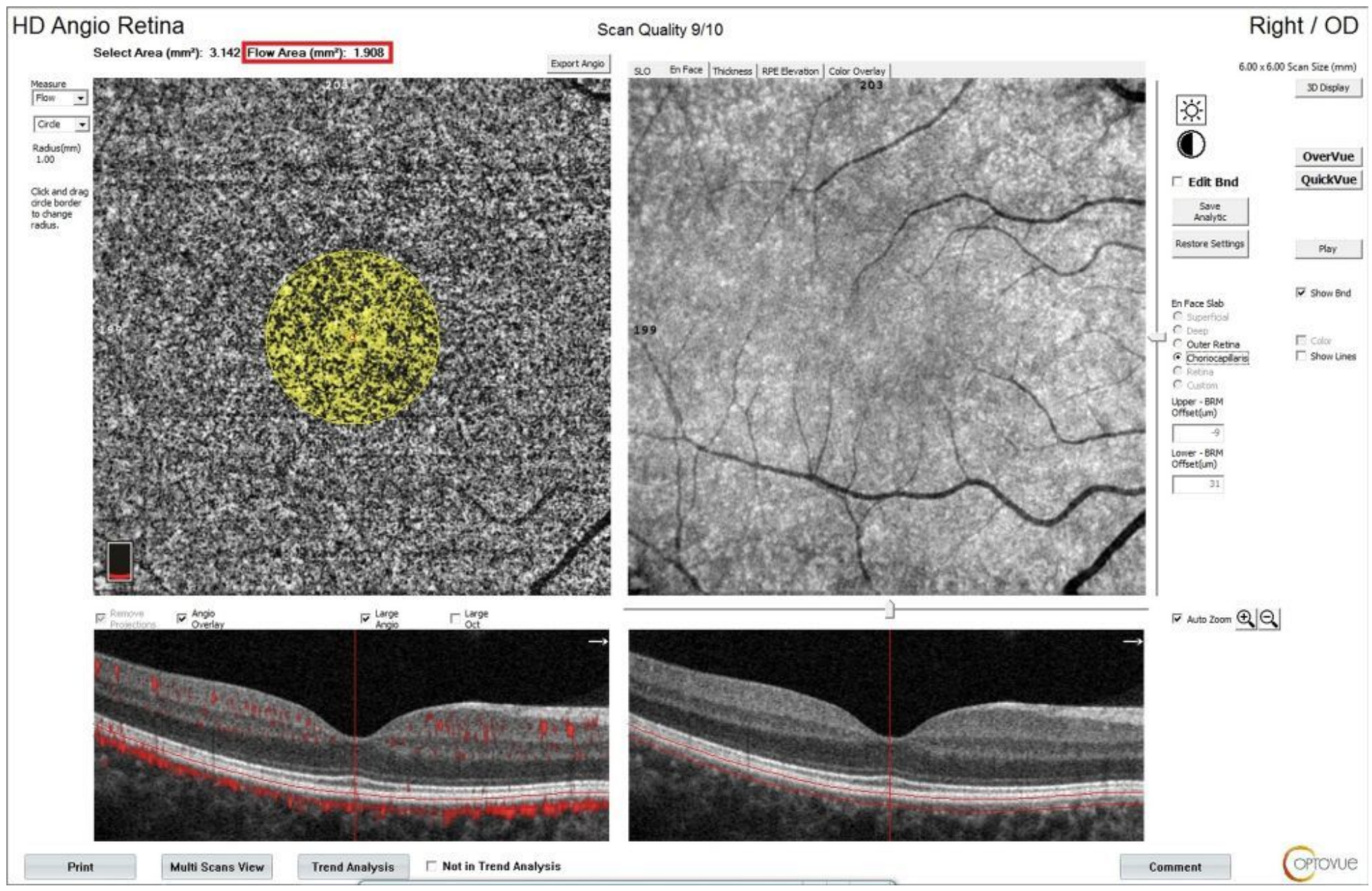

Figure 1

Pre-COVID-19 choriocapillaris blood flow value of a patient (measured as $1.908 \mathrm{~mm}^{2}$ ) 


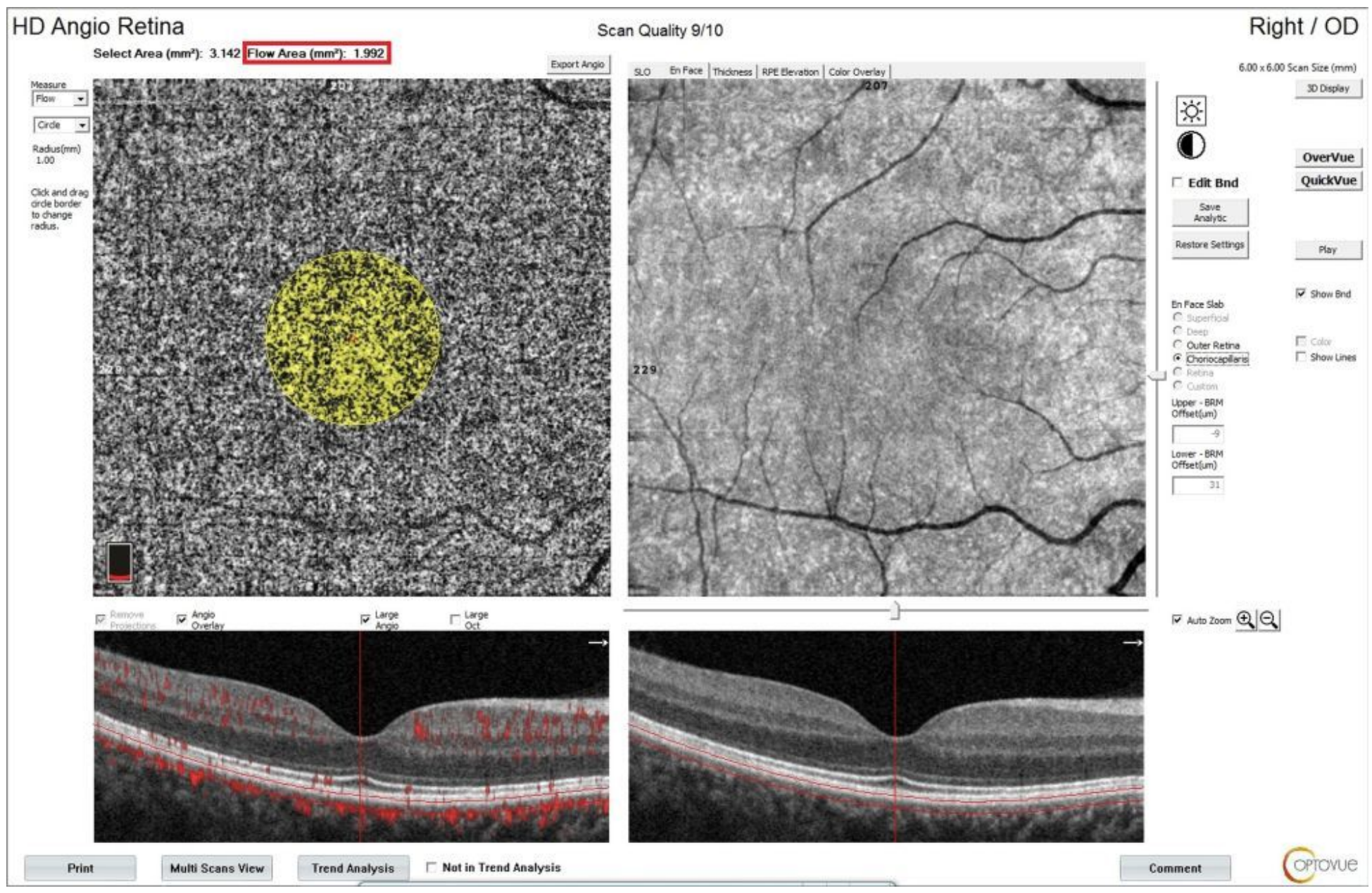

Figure 2

Post-COVID-19 choriocapillaris blood flow value of the patient presented in Figure 1 (post-disease value measured as $1.992 \mathrm{~mm}^{2}$ ) 


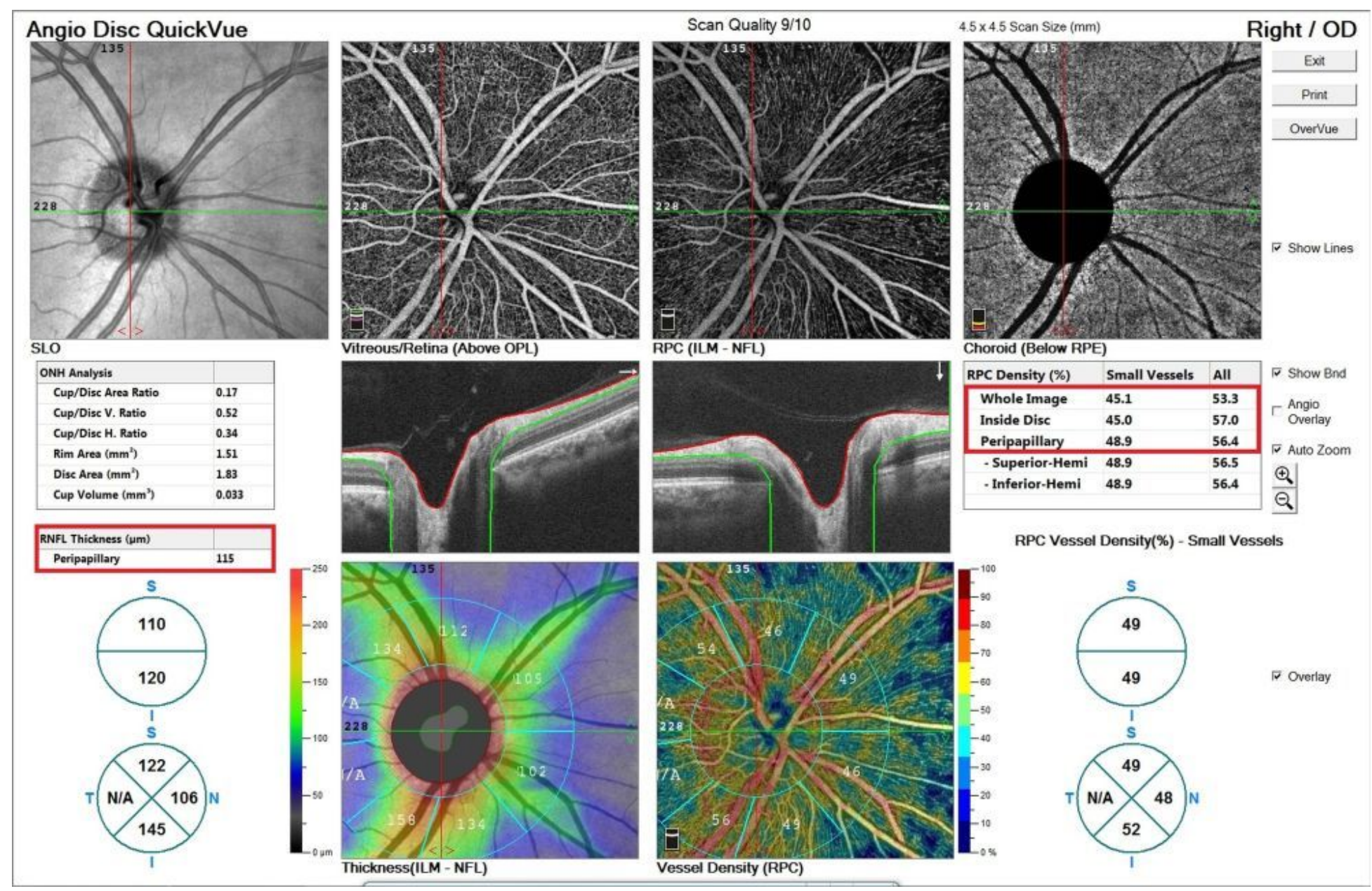

Figure 3

Pre-COVID-19 retinal nerve fiber thickness value of a patient (measured as $115 \mu \mathrm{m}$ ) 


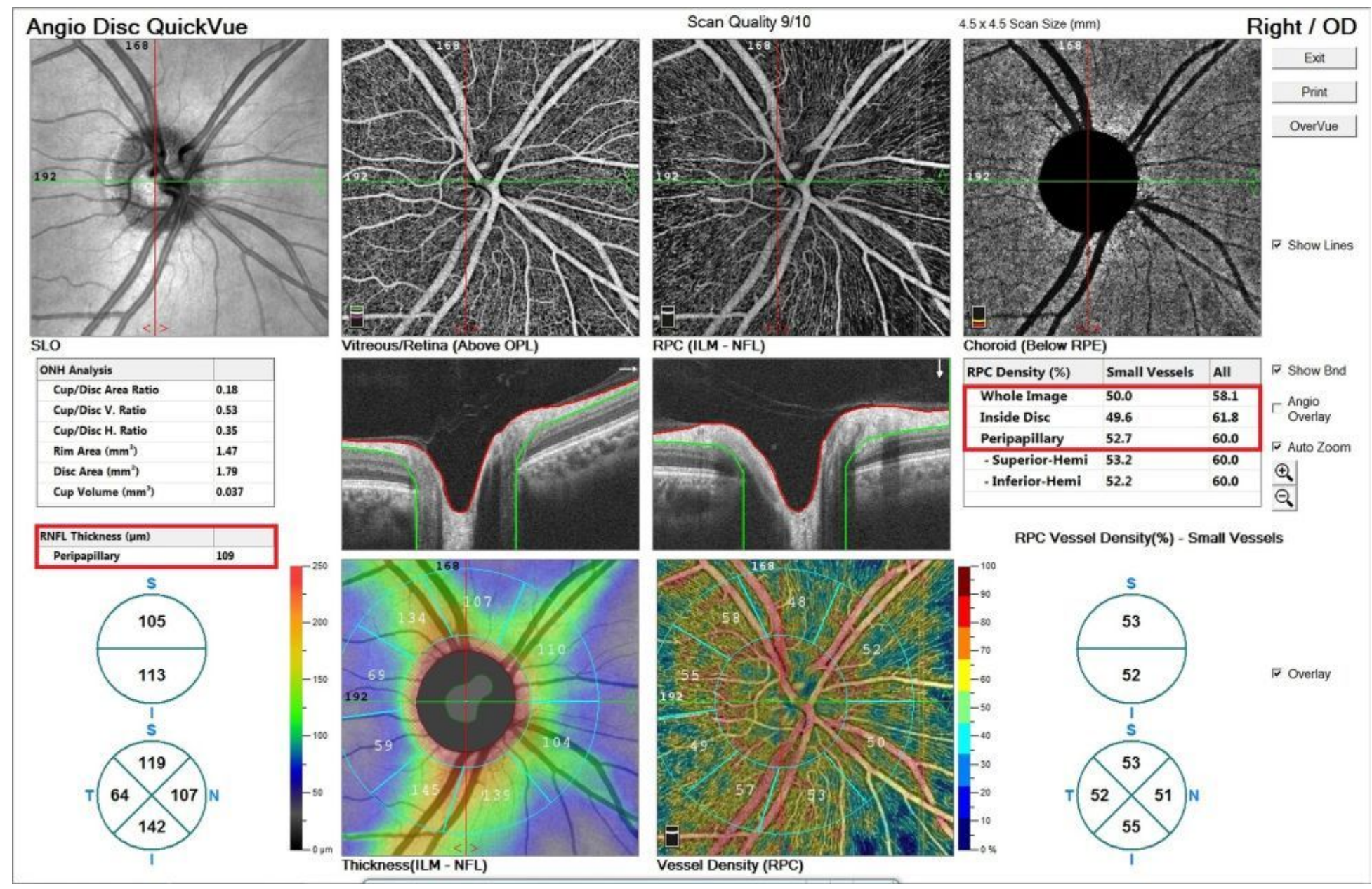

Figure 4

Post-COVID-19 retinal nerve fiber thickness value of the patient presented in Figure 3 (post-disease value measured as $109 \mu \mathrm{m}$ ) 